\title{
Soil evolution and reclamation of technogenic landscapes in Siberia
}

\author{
V.A. Androkhanov \\ Doctor of Biological Sciences, Acting Director, Institute of Soil Science and Agrochemistry, Novosibirsk, \\ Russian Federation \\ D.A. Sokolov \\ Candidate of Biological Sciences, Senior Researcher, Institute of Soil Science and Agrochemistry, Novosibirsk, \\ Russian Federation
}

\begin{abstract}
Specific features of soil evolution were revealed as a result of the longterm studies of soils developing on the coal mining spoils in Siberia. The evolutionary trends and transformation rates of young soils were shown to be determined by the spoil parent rock material, as well as by the environmental and climatic conditions of the area. Biological reclamation carried out taking into account regional soil evolution features provides the possibility a) to use the parent rock lithogenic resources more efficiently and economically, b) to avoid unfavorable combinations of parent rock properties, climate and biota species, used at the biological stage of recultivation, and c) to increase technogenic landscape diversity due to scientifically based alternation of parent rocks in spoil surface layers.
\end{abstract}

\section{INTRODUCTION}

Currently the impact of industrial production on natural landscapes of some regions in Russia reached such a level when negative consequences exert significant influence on natural processes and environment. Continuous development of mining industry, wide use of surface mining, as well as other aspects of economy increase the areas used for waste dumping. Reclamation or revegetation due to natural succession (Shrestha, Lal, 2010; 2011; Huot et al., 2015; Ahirwal et al., 2016; Feng et al., 2019) can minimize such negative consequences. Transformation of ecological functions of technogenic landscapes under both approaches result in soil cover evolution alongside with biogeocenoses succession and changes in microclimate and parent rock material. Soil evolution from the initial parent rock towards the state of equilibrium with environmental conditions is usually referred to as ontogenesis. The specificity of soil ontogenesis in technogenic landscapes is manifested by continuous changes taking place over short time spans (Ivanov et al., 2015). Following the ontogenetic one, the post-ontogenetic stage of soil evolution results in meta-stable, i.e. relatively equilibrated, soil state.

Assessing the above-mentioned soil formation features from the practical aspect makes it obvious that soil evolution process in technogenic landscapes should be aimed at spoil rock substrate transformation in such a way as to increase its beneficial soil ecological functions. The combination of such functions in the short term, i.e. at the ontogenetic stage, ensures surface compaction and vegetation cover, whereas in the medium and long term, i.e. at the post ontogenetic stage, promotes sustainability of biotic communities, able to reproduce their main components.

So the aim of the study was to reveal the regularities and specific features of soil evolution in the technogenic landscapes with the view to use the findings for increasing efficiency of reclamation approaches. 


\section{METHODS}

The soils developed on the coal mining spoils of the major coal mining areas in Siberia were used at the objects of the study. We studied the soil cover of the coal mining spoils located in the montane taiga (humid) and forest-steppe (sub-humid) areas of the Kemerovo region, in the steppe (semi-arid) areas of Khakassia and dry steppe (arid and extra continental) areas of the Tyva Republic. Some brown coal and anthracite mining sites in the Krasnoyarsk and Novosibirsk regions, where spoil parent rocks differ in metamorphosis, were also studied. The parent rock material of all spoils was not phytotoxic.

To reveal specifics of soil evolution we examined soil cover by using macromorphometry description, widely used in pedology (Rosanov, 1983). Soil identification was performed using soil classification of technogenic landscapes, a methodology developed by the Institute of Soil Science and Agrochemsitry of the Siberian Branch of the Russian Academy of Sciences (Gadzhiev, Kurachev, 1992) and then further improved by V.M.Kurachev and V.A.Androkhanov (2002). According to this classification, the identification of a corresponding diagnostic horizon allows to discriminate four types of embryozems on the surface of coal mining spoils. The so called initial embryozems do not have any diagnostic horizons that are morphologically well expressed. The OM-accumulating embryozems are distinguished by the presence of horizons where accumulation of non-specific organic matter (represented by plant material) occurs. Soddy and humus-accumulating embryozems are diagnosed by the presence of respective horizons. According to the World Reference Base for Soil Resources (World Reference..., 2015), embryozems are classified as Technosols.

The study was carried out on the horizontally leveled sites, differing in age and parent rock material.

\section{RESULTS}

The results showed that soil cover formation at the ontogenetic stage of soil evolution in different climatic environments and parent rock materials is going at different rates. All four embryozem types, i.e. initial, OM-accumulating, soddy and humus-accumulating (Table 1), were found in the studied areas. Each embryozem type corresponds to a certain stage of soil evolution, identified by the degree of visualization of OM-accumulating, soddy and humusaccumulating processes in an embryozem profile (Sokolov et al., 2015). The rate of transformation from initial into OM-accumulating and further into soddy and humus-accumulating embryozems was found to be determined by parent rock properties and climate of the regions.

Soil cover of technogenic surface layers, consisting of sandstone, is characterized by minimal diversity of soil types as compared with the soil cover developed on other dense

Table 1. Ontogenetic differentiation of soil cover composition at different technogenic substrates as dependent on environmental and climatic conditions.

\begin{tabular}{|c|c|c|c|c|c|}
\hline \multirow[b]{2}{*}{ Climate type } & \multirow[b]{2}{*}{ Sandstone } & \multirow[b]{2}{*}{ Siltstone } & \multirow{2}{*}{$\frac{\text { Parent rock material }}{\text { Mudstone }}$} & \multirow[b]{2}{*}{ Sand } & \multirow[b]{2}{*}{ Loams and clays } \\
\hline & & & & & \\
\hline Humid & EI, EOA & EI, EOA, ES & EI, EOA, ES, EHA & EOA & EOA, ES, EHA \\
\hline Sub-humid & EI, EOA, ES & $\begin{array}{l}\text { EI, EOA, ES, } \\
\text { EHA }\end{array}$ & $\begin{array}{l}\text { EI, EOA, ES, } \\
\text { EHA }\end{array}$ & EOA, ES & EOA, ES, EHA \\
\hline Semiarid & EI, EOA, ES & $\begin{array}{l}\text { EI, EOA, ES, } \\
\text { EHA }\end{array}$ & $\begin{array}{l}\text { EI, EOA, ES } \\
\text { EHA }\end{array}$ & EI, EOA & EOA, ES, EHA \\
\hline Arid & EI & EI, EOA & EI, EOA, ES & EI, EOA & EOA, ES \\
\hline Arid Extracontinental & EI & EI, EOA & EI, EOA & EI & EI, EOA \\
\hline
\end{tabular}

EI - initial embryozem; EOA - organic matter accumulating embryozem; ES - soddy embryozem; EHA humus-accumulating embryozem. 
sedimentary rocks. Such situation is due to a) significant resistance of sandstone to hypergenic transformation, and b) low (5-20\%) contribution of swelling minerals in rock cement (Ragimzade, 1992); both factors impede the formation of humus-accumulating embryozems on such surfaces and, consequently, sustainable grass communities (Glebova, 2005). As a result, in all climatic regions during 20-25 years of technogenic landscapes' existence initial embryozems comprise substantial fraction of soil cover. Under climatic conditions ranging from humid to semi-arid ones initial embryozems are accompanied by OM-accumulating embryozems, and in sub-humid regions soddy embryozems are also present in the soil cover. Notably, the same sandstone properties that limit multicomponent composition of soil cover, under humid climate promote eluvial processes in embryozems and hence the formation of woody plant communities.

More favorable conditions for soil cover differentiation occur in those technogenic landscapes, where surface layers consist of silt- or mudstone. These materials are more susceptible for hypergenic transformation as compared with sandstone and are often of laminated texture, impeding eluvial processes in embryozems. At the same time relatively high content of expansive minerals in rock cement (15-35\% in siltstone and 55-65\% in mudstone) together with carbonaceous inclusions promote formation of sustainable grass communities. All these facilitate the formation of OM-accumulating embryozems in the studied regions, with soddy embryozems developing under less arid climatic conditions (Table 1). Humus-accumulating embryozems can also develop on such parent rocks, i.e. on siltstone under sub-humid climate and mudstone under humid and semiarid climate.

Alongside with soils of the later stages of embryozem genesis, initial and OM-accumulating embryozems persist in the surface layers composed of silt- and mudstone. Such soil cover differentiation results from the differential content of stone fractions and differential metamorphosis of parent rock material.

Ontogenetic differentiation of soil cover on sands is similar to the one on sandstone. However, as soil formation on loose parent material is not accompanied by disintegration of fragments, sufficient precipitation results in practically no initial embryozems in soil cover developed over 20-25 yrs.

The best conditions for transformation of sandy substrate by pedogenic and biotic processes occur in regions with humid climate, where from the first years of phytocenoses' development soil environment benefits predominance of woody vegetation and OM-accumulating embryozems in soil cover. Under sub-humid climate due to low intensity of eluvial processes soddy embryozems contribute significantly into the soil cover. In arid regions there is minimal differentiation of soil cover, developed on sand material. This is also facilitated by deflation processes, increasing with the increased climate aridity. Frequent denudation renewal of surface sandy layers also leads to predominance of initial embryozems in the soil cover.

Clay and clay loams are the most common loose sedimentary materials of the coal mining spoils in Siberia. Transformation of such surface spoil layers, similar to the sandy ones, by pedogenic and biogenic processes begins in the substrate, most favorable for soil formation. High content of fine-sized fractions results in formation of soddy and humus accumulating embryozems over 20-25 years of revegetation.

Soil cover differentiation at the post ontogenetic stage of evolution occurs after embryozems reach meta-stable stage of development. At this stage soil transformation occurs mainly as changes in properties of organogenic horizons. The main driver of the process is substitution of the successional stages of phytocenoses with climax communities, adequate for the surrounding natural environment and climatic conditions. In different regions such substitution does not occur in a similar way. Under moderate arid and humid conditions the meta-stable state as a result of soil evolution is reached at the stage of a closed phytocenosis (Glebova, 2005). In arid conditions the meta-stable state is reached when various sagebrush species become predominating over legumes (Titlyanova, Sambuu, 2016). In humid conditions the meta-stable state of soils is reached when tree crowns close and surface illumination regime changes.

The described changes in phytocenoses directly affect the properties of the upper part of soil profile, allowing more detailed diagnostics of surface differentiation according to soil 
formation conditions. In embryozems with the same sequence of genetic horizons it becomes possible to diagnose processes in order to ascribe soils to a certain subtype. There was a need to identify soil subtypes on the old (20-25 yrs) coal mining spoils in Siberia. So among initial embryozems, along the usually identified typical subtype, common at the initial stages of parent substrate transformation by pedogenic and biogenic processes, a cryptopedogenic subtype was distinguished. Such initial cryptopedogenic subtypes are formed after initial embryozems reach the meta-stable state, and thus usually develop on substrates with low lithogenic potential for soil formation. Similar to initial ones, the cryptopedogenic embryozems do not visually manifest genetic horizons, the presence of which more often results from the absence of conditions for preservation, rather than formation.

The soil type of OM-accumulating embryozems can be differentiated into three subtypes according to soil forming environment. For example, the soils with their type-identifying horizon represented by herbs and grasses' residues, are referred to as OM-accumulating felt embryozems; in litter and peat subtypes this horizon is represented by tree litter and moss phytomass.

The identification of soddy embryozem subtypes is more complicated. A combination of features is used to discriminate between xerophytic and hygrophytic subtypes, including the character of interaction between the type-diagnostic horizon with the underlying mineral soil, as well as the composition of the horizon above the soddy one, with sedge residues contributing significantly into the litter of the latter one.

Because humus-accumulating embryozems can form in a quite narrow range of climatic and lithogenic conditions, their differentiation into subtypes according to soil formation conditions is rather problematic. Identified earlier as an individual soil type (Gadzhiev, Kurachev, 1992), currently coarse humus-accumulating embryozems are considered to be a subtype of humus-accumulating embryozems. We believe their development results from the transformation of humus-accumulating horizon, developed during the preceding stage of grass vegetation, rather than from specific humus accumulation in technogenic forest ecosystems.

As post ontogenetic stage of soil evolution starts simultaneously with establishment of constant phytocenotic structure, its specific moment of establishment varies due to conditions, determining the syngenetic transformation of substrate by pedogenic and biogenic processes. It was shown to take 25-26 years under the most favourable conditions in Siberia, i.e. on clay loamy spoils in Kansk-Achinsk coal mining region in Central Siberia (MironychevaTokareva, 1998). On substrates formed by dense sedimentary rocks sustainable soil cover can be developed over 50 years or more (Kurachev, Androkhanov, 2002).

Alongside with soil cover features, mentioned above, another characteristic feature of metastable soil cover is not only its temporal stability, but also its constant composition irrespective of heat- and water supply in some years or over a period of several years. This peculiarity results in low soil cover differentiation on territories composed of the same parent rock material. Such stability of soil cover can best be seen in pedogenesis under humid conditions on sandstone material (Table 2). Development and closinging of tree crowns ensures plant litter input practically on entire soil surface. Similar situation can be observed under sub-humid climate with an exception that the sites with herb and grass communities are dominated by the subtype of soddy xerophytic embryozems. Pedogenesis under arid conditions on sandstone results in formation of OM-accumulating felt embryozems. With increasing climate aridity the contribution of this subtype into soil cover becomes less than the one of the initial cryptopedogenic embryozem subtype.

On siltstone surface layers soil cover differentiation at the stage of its stabilization is mostly driven by the same factors as on sandstone spoils. However, due to the production of finesized particles from siltstone material via its destruction, the formation of humusaccumulating and soddy xerophytic embryozems becomes possible in sub-humid and semiarid climatic conditions, respectively. In regions with typical arid climate this siltstone characteristic results in the dominance of the OM-accumulating felt embryozems.

In regions where spoil parent rock material is mudstone (Table 2), soil cover in technogenic landscapes is the most differentiated. High variability of mudstone properties resulted in the prevalence of OM-accumulating litter embryozems and coarse humus accumulating 
Table 2. Post ontogenetic differentiation of soil cover developed on different substrates in the technogenic landscapes under different climatic conditions.

\begin{tabular}{|c|c|c|c|c|c|}
\hline \multirow[b]{2}{*}{ Climate type } & \multirow[b]{2}{*}{ Sandstone } & \multirow[b]{2}{*}{ Siltstone } & \multirow{2}{*}{$\frac{\text { Parent rock material }}{\text { Mudstone }}$} & \multirow[b]{2}{*}{ Sand } & \multirow[b]{2}{*}{ Loams and clays } \\
\hline & & & & & \\
\hline Humid & EOAl & EOAl & $\begin{array}{l}\text { EOAl, EOAp, } \\
\text { EHAch }\end{array}$ & EOAl & $\begin{array}{l}\text { EOAl, ESh, } \\
\text { EHAch }\end{array}$ \\
\hline Sub-humid & EOAl, ESx & ESx, EHA & ESx, ESh, EHA & ESx & EHA \\
\hline Semiarid & EOAf & $\begin{array}{l}\text { EOAf, } \\
\text { ESx }\end{array}$ & EOAf, ESx, EHA & $\begin{array}{l}\text { EOAf, } \\
\text { ESx }\end{array}$ & EHA \\
\hline Arid & $\begin{array}{l}\text { EIC, } \\
\text { EOAf }\end{array}$ & EOAf & EOAf, ESx & EOAf & ESx \\
\hline $\begin{array}{l}\text { Arid } \\
\text { extracontinental }\end{array}$ & EIc & EIc, EOAf & EIc, EOAf & EIc & EOAf \\
\hline
\end{tabular}

EIc- initial cryptopedogenic embryozem; EOAl - organic matter accumulating litter embryozem; EOAf organic matter accumulating felt embryozem; EOAp - organic matter accumulating peat embryozem; ESx soddy xerophytic embryozem; ESh - soddy hygrophytic embryozem; EHA - humus accumulating embryozem; EHAch - coarse humus accumulating embryozem.

embryozems in soil cover of the humid regions. OM-accumulating peat embryozems develop on highly compacted surface layers, composed of highly metamorphosed mudstone. Under sub-humid climate the dominant OM-accumulating embryozems are substituted by humus accumulating and soddy xerophytic and hygrophytic ones. With further increase in aridity the share of the above-mentioned soils in the soil cover decreases, whereas the share of OMaccumulating felt embryozems increases. Under arid extra continental climate the contribution of initial cryptopedogenic embryozems becomes more pronounced.

Soil cover composition on sand rock is similar to the one on sandstone. However, high dispersion, resulting in the relatively high water-holding capacity of sands, shifts pedogenesis towards prevailing formation of soddy xerophytic embryozems in sub-humid and semi-arid regions and towards $\mathrm{OM}$-accumulating felt embryozems in arid regions.

Soil cover differentiation at the post ontogenetic evolution stage is less pronounced in loamy and clay surface layers, as their properties promote quick implementation of specific zonal soil formation. Thus more than 20-years-old areas of coal mining spoils, composed of such parent rock material, display similar soil cover composition in most climatic regions except for the humid ones, where soddy hygrophytic embryozems are widely spread alongside with OM-accumulating litter embryozems, with" residual" coarse humus accumulating embryozems being often identified as well.

\section{CONCLUSION}

Thus our studies showed different potential of parent rock substrates for pedogenesis and differentiated soil cover formation in technogenic landscapes, as related to embryozem types and subtypes. Taking into account that each soil type and subtype under different climatic conditions develops under certain vegetation formation, one can design adequate approaches for technical and biological reclamation. The latter, based on the revealed features of soil evolution, allows to 1) use lithogenic resources more efficiently and economically; 2) to minimize or avoid those combinations of parent rocks, climatic conditions and plant species, which are unfavourable for pedogenesis; 3 ) to increase biological diversity of technogenic landscapes by reasonably alternating parent rock materials in surface layers.

Overall it can be concluded that parent rock substrates with higher content of physical clay or that are able to produce it due to weathering, i.e. clays, loams, mudstone, are more beneficial for greenery landscaping. The less metamorphised the parent rocks are, the higher their 
capacity to release fine-sized fractions is, and hence better the chances to reach the reclamation goals. Mechanic fixing of a surface, i.e. providing geomorphologic stability for a landscape, requires other parent rock substrates. In such cases dense sedimentary materials, resistant to hypergenic transformation (sandstone, strongly metamorphised siltstone and mudstone) are better. The mentioned features enable development of efficient and economically relevant reclamation actions. Their implementation is possible by employing selective spoil formation by using loose or alternating dense sedimentary parent materials for surface layer construction in technogenic landscapes.

\section{REFERENCES}

Ahirwal, J. \& Maiti S.K. 2016. Assessment of soil properties of different land uses generated due to surface coal mining activities in tropical Sal (Shorea robusta) forest, India. Catena 140: 155-163.

Feng, Y., Wang J., Bai Z. et al. 2019. Effects of surface coal mining and land reclamation on soil properties: A review. Earth-Science Reviews 191: 12-25.

Gadzhiev, I.M. \& Kurachev V.M. 1992. Genetic and environmental aspects of the study and classification of soils of technogenic landscapes. In V.G. Mordkovich, V.I. Volkovintser \& T.P. Slavlina (eds), Ecology and remediation of technogenic landscapes: 6-15. Novosibirsk: Science. Sib. Br. [in Russian]

Glebova, O.I. 2005. Biogeographic diagnosis of Kuzbass embryozems. Novosibirsk: Institute of Soil Science and Agrochemistry SB RAS. [in Russian]

Huot, H., Morel J.L. \& Simonnot, M.-O. 2015. Pedogenetic trends in soils formed in technogenic parent materials. Soil Sciences 180 (4-5): 182-192.

Ivanov, I.V. \& Kudeyarov, V.N. 2015. Evolution of soils and soil cover. Theory, diversity of natural evolution and anthropogenic transformations of soils. Moscow: GEOS. [in Russian]

Kurachev, V.M. \& Androkhanov, V.A. 2002. Classification of soils of technogenic landscapes. Siberian Journal of Ecology 9 (3): 255-261. [in Russian]

Mironycheva-Tokareva, N.P. 1998. Dynamics of vegetation during overgrowing of dumps (on the example of KATEK). Novosibirsk: Science. Sib. Br. [in Russian]

Ragim-zade, F.K. 1992. Soil-forming rocks of technogenic landscapes. In V.G. Mordkovich, V. I. Volkovintser \& T.P. Slavlina (eds), Ecology and remediation of technogenic landscapes: 15-45. Novosibirsk: Science. Sib. Br. [in Russian]

Rozanov, B.G. 1983. Soil morphology. Moscow: MSU Pubs. [in Russian]

Shrestha, R.K. \& Lal, R. 2010. Carbon and nitrogen pools in reclaimed land under forest and pasture ecosystems in Ohio, USA. Geoderma 157 (3): 196-205.

Shrestha, R.K. \& Lal, R. 2011. Changes in physical and chemical properties of soil after surface mining and reclamation. Geoderma 161 (3-4): 168-176.

Sokolov, D.A., Androkhanov, V. A., Kulizhskii, S. P. et al. 2015. Morphogenetic diagnostics of soil formation on tailing dumps of coal quarries in Siberia. Eurasian Soil Science 48 (1): 95-105.

Titlyanova, A.A. \& Sambuu, A.D. 2016. Succession in grasslands. Novosibirsk: Publishing house of the SB RAS. [in Russian]

World reference base for soil resources 2015. International soil classification system for naming soils and creating legends for soil maps. Update 2015. World soil resources reports, 106. Food and agricuture organization of the United Nations. Rome. 